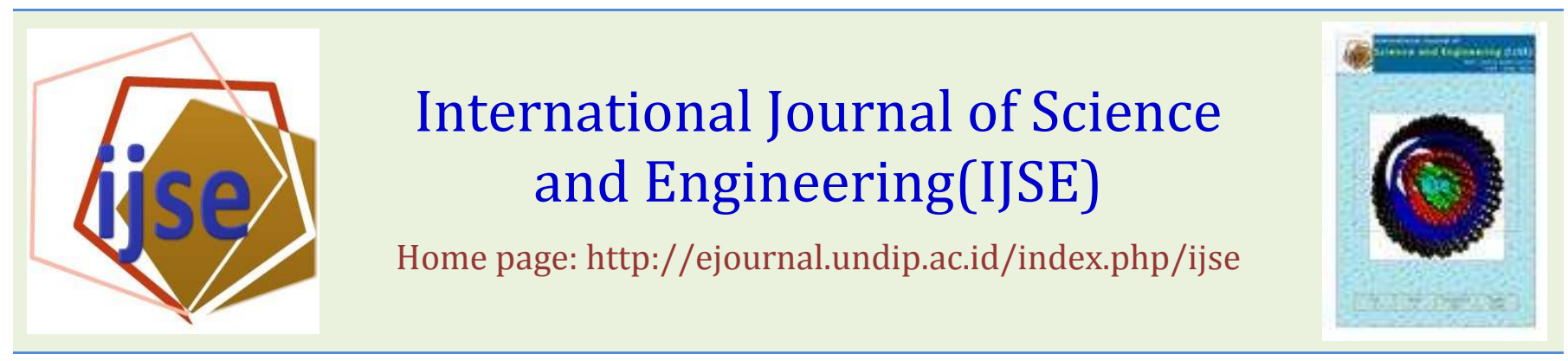

\title{
New Concept of Cultivation Using Limited Strip-Tillage with Strip Shallow Irrigation
}

\author{
Yazid Ismi Intara ${ }^{1)}$, A. Sapei ${ }^{2}$, Erizal ${ }^{2}$, Namaken E. $S^{3}$, M. Bintoro Joefrie ${ }^{4}$ \\ ${ }^{1)}$ Agricultural Faculty of Mulawarman University, Kampus Gunung Kelua Samarinda, East Kalimantan 75123 \\ 2) Civil and Agricultural Environment Department of Agricultural Technology Faculty, Bogor Agricultural University (IPB), 16000. \\ 3) Bio-system Engineering Department of Agricultural Technology Faculty, Bogor Agricultural University (IPB), Bogor 16000 \\ 4) Agronomic and Horticulture Department of Agricultural Faculty, Bogor Agricultural University (IPB), West Java, Bogor 16000
}

Email: izmi_6@yahoo.com, asep_sapei@yahoo.com

\begin{abstract}
Dry land is one of land resources which potentially used for food crop cultivation, especially in the areas which have light to medium technical obstacles. The development of technology to improve soil quality in marginal lands to be productive lands is still widely open for agricultural development in Indonesia. Rooting medium quality can be improved by changing soil tillage method and observing the proper crop irrigation technology. It can be the solution for crop cultivation in clay loam soil. This study aimed to obtain water movement model in a minimally-tilled clay soil with strip shallow irrigation. The concept is limited soil-tillage with strip shallow irrigation method, water supply technique, and crop water requirement. Method used in this study includes developing water movement model (software development) in a minimally-tilled clay soil with subsurface irrigation. In the final stages, research also conducted water movement analysis testing apparatus in the laboratory, field validation of the subsurface irrigation performance, and cultivation technique testing to chili pepper growth (Capsicum annuитL.). The development of water movement simulation on a limited strip-tillage with subsurface irrigation uses the concept to quantify the amount of water in the soil. The analysis of movement pattern was demonstrated on contour patterns. It showed that the wetting process can reach depth zone $-5 \mathrm{~cm}$ to the rooting zone. It was an important discovery on the development of minimum stripe tillage soil with subsurface irrigation. Specifically, it can be concluded that: the result of fitting by eyes to diffusivity graphic and water content obtained the required parameter values for soil physical properties. It was then simulated on horizontal water movement model on a minimum strip-tillage with strip shallow irrigation.
\end{abstract}

Keywords: limited strip, tillage, shallow irrigation, water modeling(;)

Submission: March 23, $2014 \quad$ Correction: April 11, 2014

Accepted: April 14, 2014

Doi: 10.12777 ijse.6.2.169-173

[How to cite this article: Yazid Ismi Intara, A. Sapei, Erizal, Namaken E. S, M. Bintoro Joefrie. 2014. New Concept of Cultivation Using Limited StripTillage with Strip Shallow Irrigation, International Journal of Science and Engineering, 6(2),169-173. Doi:10.12777/ijse.6.2.169-173]

\section{InTRODUCTION}

Conventional soil tillage in its application in the field eventually results in more works than minimum tillage (Kelly et al., 1996). One of the minimum tillage concepts is strip-tillage or a form of conservation tillage in which only row zones are tilled, leaving the 9- to 12 -inch inter-row zone undisturbed and the soil is not plowed (Morrison, 2002). One of the advantages of applying strip-tillage is it allows for a better seedbed for plant growth than conventional tilling, lower energy requirement, and undisturbed surface between rows acts as erosion repellent. Strip-tillage provides supportive environment for planting seeds in a row (Janovick et al., 2006). It also helps increasing infiltration velocity (Mukhtaret et al.,
1985), as well as improving not only water availability for crops along the root zone but also water recharge (Trouse 1983).

Soil tillage is an alternative which can help solving the problems in marginal areas with clay loam texture (podzolic), other alternatives should be considered in the selection of land irrigation technology. By selecting several irrigation technology alternatives, it is found that subsurface irrigation is more appropriate for marginal lands or clay loam soil (podzolic). Clay soil is usually characterized by its slow permeability and shallow subsoil. It inhibits the root growth and eventually reduce production. Thus, an optimum addition of irrigation water is needed for crop planting using subsurface irrigation 
system installed in certain depth below surface drainage (Mostaghimi and McMahon 1989).

In limited soil tillage, the maintenance is simple and can beconducted easily. Moreover, soil will transport the water more effectively. Subsurface irrigation management is targeted to achieve relative soil aggregates. Soil aggregate stability can be repaired by the addition of organic matter. Hardjowigeno (1986) stated that the proper amount of groundwater for plants has certain limits. The excess or lack of water will damage the plant growth. Strelkoffet et al. (2004) explained that the solving the hydraulic equation of unsteady flow in an irrigation channel is approached with available infiltration or up filtration formulation in flow resistance parameters as well as water channel design testing. The analysis is only the proof of performance prediction for data input accuracy. Through the analysis on porous medium (soil), water will move if potential gradient occurs. Flow flux on saturated porous medium has been discovered by Darcy (Bear and Verruijt, 1987; Miyazaki et al., 1993). Water movement on the ground is closely related to soil hydraulic conductivity even though it has no fixed value, but diminishing as the water content decreases or equal to the declining of groundwater matrix suction (Yong and Warkentin 1966). Water movement phenomenon is a part of wetting and drying process which displayed the difference among hydraulic conductivity with volumetric moisture content and matrix suction (Jansen 1980). Thus, moisture retention characteristic curve displayed the phenomena of capillarity pressure (matrix suction) and water content is important and basic in an analysis of water and solution transportation on vadoze zone (van Genuchten, 1980).

Limited soil tillage cultivation is developed to striptillage with subsurface irrigation only for seasonal crop cultivation. It can be applied as the alternative of marginal land utilization. The study aimed to: obtain the combination of soil texture and the addition of organic matter to water availability, study the management of soil moisture in the root zone and analyze the experimental design compare to soil physics concepts.

\section{RESEARCH METHOD}

The modeling of water content movement in striptillage is conducted independently using portable computer with software of Microsoft Excel, Visual Basic Editor, and Surfer version 8 to create contour.

Soil diffusivity experiments (investigation of the diffusion equation) with horizontal water movement (horizontal column) as proposed by Bruce and Klute (1956) was conducted in the laboratory. The development of water movement simulation in strip-tillage with subsurface irrigation uses the concept to quantify the amount of ground water. There are two approaches: volumetric water content, $\theta$ (water volume) and matrix suction $(\mathrm{cm})$ or pressure head, h $(-\mathrm{cm})$. Furthermore, the result from simulation program is converted to contour after being processed with Surfer software. This procedure will make the existed flow pattern is a lot easier to analyze.
The cultivation technique was tested to see its effect on plant sample growth. It was carried out in the dry land with high clay content. The materials are clay loam soil (podzolic), organic matter (compost), water for strip shallow irrigation, and chili seeds. The testing design used Completely Randomized Design, with two factors: water supply schedule (A) and the dosage of compost (K). Water supply factor consists of two types: A1 (once-a-day watering, in the morning) and A2 (twice-a-day watering, in the morning and evening), while the addition of organic matter consists of 4 levels: without organic matter K0, K1 $(1.5 \mathrm{~kg}), \quad \mathrm{K} 2 \quad(3 \mathrm{~kg})$, and $\mathrm{K} 4 \quad(4.5 \mathrm{~kg})$.Completely randomized design was conducted with three replications.

Those aspects are made into a concept design of a cultivation technique for seasonal crop and combining the limited strip-tillage method with strip shallow irrigation as it is shown in Figure 1.

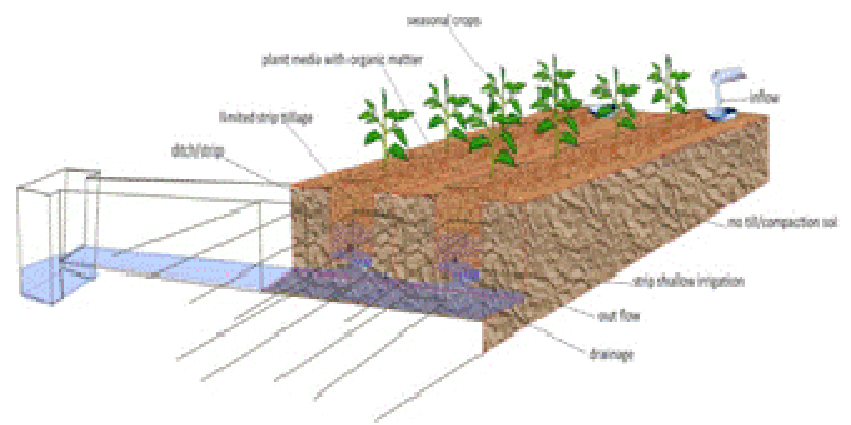

Figure 1. The initial concept of cultivation development technique for seasonal crop with limited strip-tillage and strip shallow irrigation

\section{RESULT AND DISCUSSION}

Dry land is one of land resources and potential for food crop cultivation, especially in the areas having light to medium technical obstacles (shown in Fig. 2). To improve soil productivity, the introduction of organic matter and chemical fertilizer are needed. More over, it is important to apply proper soil tillage and the concept of soil and water conservation. The development of technology to improve soil quality in marginal lands to be productive lands is still widely open for agricultural development in Indonesia.

Rooting medium quality can be improved by changing soil tillage method and applying proper irrigation technology. When the rooting medium is repaired, the soil quality of marginal region is improved. The effort to improve soil quality is focused on the reclamation of exmining areas to be productive farms. The cultivation technique that improves the soil tillage irrigation technology can be the alternative for land quality improvement. 


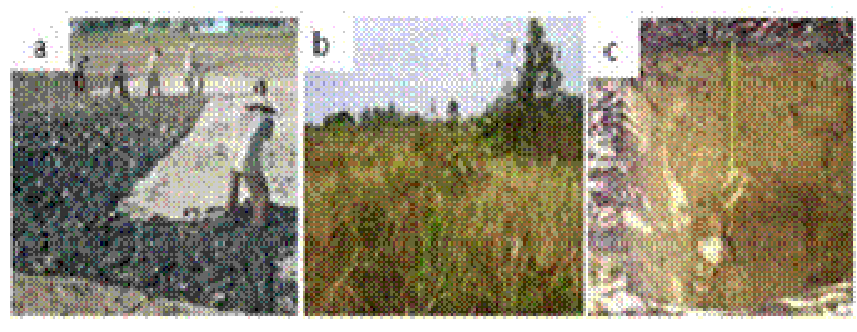

Figure2. a) In general, soil tilling in Indonesia is conducted conventionally, b) Marginal lands are targeted for agricultural land expansion in the future, and c) Yellow-brick podzolic soil is one of marginaltypes soil with clay loam texture

The explanations mentioned above is the foundation for the improvement and correction in seasonal crop cultivation method that is specific to location. The aspects to support the improvement are:

$>$ First aspect: the alternative soil tillage technology proposed in this study is strip-tillage method. In general, tillage is the agricultural preparation of soil to provide proper soil physics characteristics for crop growth. Minimum tillage (strip) has several advantages compared to other soil tillage methods.

$>$ Second aspect: the irrigation for the area, which considers the land condition (marginal land with clay loam texture). It applies shallow subsurface irrigation.

$>$ Third aspect: modifying the two methods mentioned above by combining both techniques and resulting in a cultivation technique for seasonal crop. It provides ET crop in the rooting zone and minimum tillage for land conversion. The surface areas between the rows enable easier crop nurturing.

The research application acts as an alternative for marginal lands improvement for clay loam soil. The cultivation technique focused on irrigation which caused water movement distribution in tilled soil. Water flow movement is analyzed within the boundaries and it is a new invention. It also enables the development for further cultivation technique. The development according to adopted soil tillage from minimum strip tillage so that it has basic difference with the previous cultivation technique for seasonal crop (Intara et al., 2013).

The innovation is focused on the cultivation technique of seasonal crop from the combination of limited striptillage with strip shallow irrigation and water supply technique for fulfilling crop water use in a strip row and has the mean of conservation (land reclamation).

The development technique is divided into three main parts: (a) crops and rooting medium; (b) strip, and (c) irrigation and drainage. The description of cultivation technique for seasonal crop is described below: the crop for this study is a seasonal crop (chili pepper) which can be harvested in less than 4 months. Rooting medium was soil from the strip (trench) and added with compost. Strip was made of rectangle block with 2-4 m long, $0.2 \mathrm{~m}$ wide, and $0.2 \mathrm{~m}$. Its top, right, and left side was left open and made of compacted soils. Its sides could be made either permanent or semi-permanent in order to be used repeatedly by only repairing the rooting medium. The trench floor was made water proof with the slope $2-3^{\circ}$ that can be made only from compacted soils. Irrigation system (shallow susbsurface irrigation) was made from manual/traditional irrigation (intermiten), where the water container was placed at the upstream. There were holes at the bottom side of water container that lead to irrigation channel and end up in the field. Drainage system at the down stream served to prevent excess water, especially during the rainy season.

Considering the conditions previously mentioned, this study was strengthened with scientific analysis as the foundation for further research. The analysis included water movement model on a limited strip-tilled clay soil with subsurface irrigation. It generated information regarding soil physical properties data and a measuring instrument (interface) along with a set of testing apparatus are made to analyze the water flow in tilled soil. It followed by water flow analysis in a set of experiments in the laboratory and field validation of subsurface irrigation performance on shallow tilled soil. The final testing was the cultivation technique and its effect to plant growth.

Water distribution in unsaturated state soil is capillary rise. It occurs in the ground because cohesion and adhesion are greater than gravity. It can move side ways or upward due to capillary force. Some of capillary rise is available water (absorbable) for the plants.

Preliminary research was carried out to gain the soil physical properties data for no-tilled and minimum-tilled soil. It was to explain the result which showed good drainage in the firm soil and rather poor drainage in the strip-tillage soil (water absorbed by till soil aggregate is limited). The irrigation performance efficiency in the limited strip-till apparatus box with subsurface irrigation showed less efficient result caused by unstable soil texture. Primary research was conducted in field, to observe the irrigation performance and its effect to seasonal crop. The selected field should meet the criteria of marginal lands so that the land conservation using limited strip-till method with strip shallow irrigation would present improvement after the proposed method is applied (Fig. 3). Irrigation performance demonstrated the effective wetting of strip-tillage only in short track irrigation channels $<5 \mathrm{~m}$. It is suitable for subsystem field management or to repair traditional field.
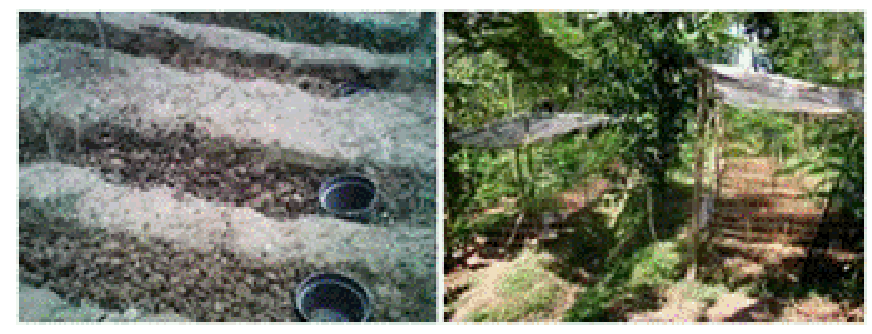

Figure 3. Selection of suitable area for traditional field approach with silty clay loam-textured soil, podzolic type

Preliminary research regarding soil texture selection and organic matter addition to water availability showed that clay-textured soil has lower evaporation level than clay loam soil. The addition of organic matter (compost) on clay-textured soil could increase ground water content 
and water availability and reduce soil volume (Intara et al., 2011). The research was continued on main research which applied development cultivation technique approach of tested crops in the field to manage soil moisture in the root zone. It aimed to maintain the moisture or water content to be available when needed by the crops.

Design testing data recapitulation of chili pepper showed that the addition of organic matter gave significant effect to plant growth. On the contrary, water supply parameter gave no significant effect to plant growth. It indicated quantitative statistic calculation led to agronomic explanation while the qualitative observation of crop graphic growth showed watering level once a day gave better effect to plant water availability, except the addition of organic matter (K3) caused more water bounded around the root zone which eventually gave negative impact when the root growth had reached wetting zone water table.

Crops acted as control (K0) without the addition of organic matter showed stagnant growths which were really different with crops with the addition of organic matter (K2 and K3). Crops with organic matter (K2 and K3) grew normally both the stem and root. It was due to fluctuated ground water concentration influenced by irrigation water and water concentration depends on ambient factors (including the addition of organic matter). Moreover, chili pepper as testing crop of strip-tillage with strip shallow irrigation was widely known sensitive to excess water (Intara et al., 2011).

Modeling the movement of water movement in striptillage with subsurface irrigation was carried out using visual basic editor in Excel. From fitting by eyes test on diffusivity graph and water content, the desired parameter values were obtained for formulating soil physical properties. It was then simulated on horizontal water movement model of strip-tillage with subsurface irrigation. The data were applied to the development of simulation concept in water movement. It used the concept to quantify the amount of groundwater, consists of two approaches: volumetric water content, $\theta$ (water volume) and matrix suction $(\mathrm{cm})$ or pressure head, $\mathrm{h}$ $(-\mathrm{cm})$. It was followed by converting simulation data to contour after being processed using Surfer 8 software. By converting, it made the display was easier to observe.

Movement patterns displayed on the contour pattern showed wetting process could reach the depth zone up to $(-5 \mathrm{~cm})$ to the root zone and it became an important discovery in order to develop the concept of strip-tillage with strip shallow irrigation. The water movement occurred according to contour model can be explained as follows: the cracks encountered turbulence caused by water pressure in the vicinity of the base appropriate with water pouring pressure. It was followed by spread, storage, and depletion process of water content. The validation results of water content distribution patterns at each research stage are shown in Figure 4.

In the developed model system, it demonstrated that the wetting patterns take time to achieve balanced water content distribution. It emphasized that the novelty of developed system was the strip shallow irrigation with water content movement to maintain the moisture of strip-tilled soil in order to provide water availabilty for crops as it is shown in Figure 5.

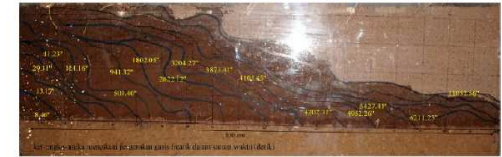

isual wetting pattern from longitudinal section of acrylic hox

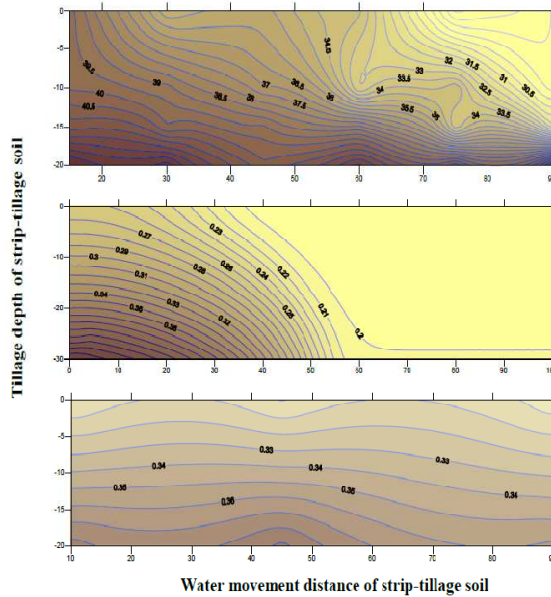

The distribution pattern of water intent from reading (n)

The distribution pattern of water content from water movemeut simulatio
model program

Figure 4. Validation of water content distribution pattern (volume base) as a result of water movement study on limited strip-tillage with strip shallow irrigation system.

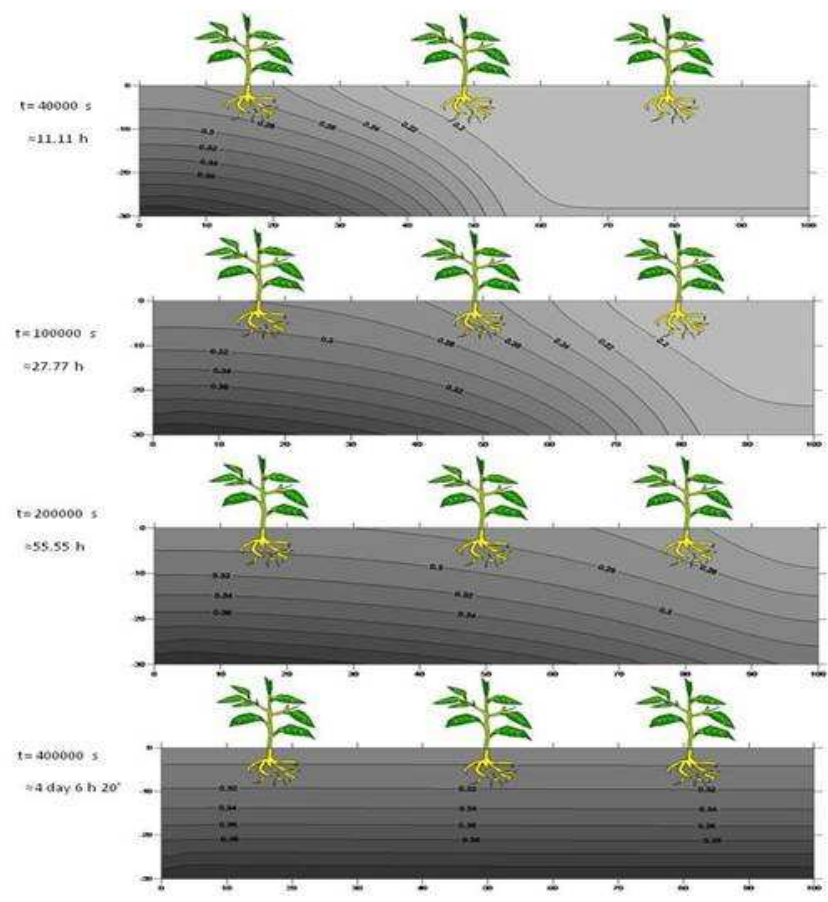

Figure5. Illustration of the changes in wetting distribution pattern (volume base) to time period on striptillage with strip shallow irrigation in order to maintain soil moisture and water availability

In the manual system, the wetting process would be less balanced at first, where the base had more wetting process than the endpoint near the outlet because of less perfect wetting. The cracks encountered turbulence caused by water pressure in the vicinity of the base appropriate with water pouring pressure. In the water content spread, storage, and depletion process, flow in the 
system could be described by several phases (Jansen 1983), which are: 1) spread phase, occurs in irrigation total duration, water is distributed from the base to the outlet. 2) storage phase, occurs in total duration from the end of water distribution to the discontinuation of irrigation water. 3) depletion phase, occurs in total duration from the discontinuation of irrigation water to the beginning of recession in the base. It was caused by limited amount of water on limited manual system even though it was enough to maintain soil moisture of tillage medium which was estimated only last for \pm 8 hours.

\section{CONCLUSION}

The development concept of cultivation technique which is tested in the field was the soil moisture management in rooting zone. It was due to maintain soil moisture around the root zone or to provide water needed by the crops. Irrigation performance showed the results that effective wetting of strip-tillage could be developed only in short track irrigation channels $<5 \mathrm{~m}$. It was suitable for subsystem field management or to repair traditional field.

Design testing data recapitulation showed that the addition of organic matter gave significant effect to plant growth. On the contrary, water supply parameter gave no significant effect to plant growth. More over, chili as testing crop was widely known sensitive to excess water.

The development of simulation concept regarding water movement used the concept to quantify the amount of ground water, consists of two approaches: volumetric water content $\theta$ (water volume) and matrix suction $(\mathrm{cm})$ or pressure head, $\mathrm{h}(-\mathrm{cm})$.From fitting by eyes test on diffusivity graph and water content, the desired parameter values are obtained for formulating soil physical properties. It was then simulated on horizontal water movement model of limited strip-tillage with subsurface irrigation. Movement patterns displayed on the contour pattern showed wetting process could reach the depth zone up to $(-5 \mathrm{~cm})$ to the root zone and it became an important discovery in order to develop the concept of strip-tillage with strip shallow irrigation.

\section{REFERENCES}

[1] Bear J and Verruijt. 1987. Modeling Groundwater Flow and Pollution. D. Reidel Pub. Co. Tokyo

[2] Bruce R R and Klute A. 1956. The Measurement of Soil Water Diffusivity. Soil Sci. Soc. Am. J. (20); 458-452

[3] Hardjowigeno S. 1986. Ilmu Tanah. Jurusan Tanah (in bahasa). Faperta. IPB. Bogor.

[4] Intara Yazid I., A Sapei, Erizal, E. N Sembiring and M. B Joefrie. 2011. Mempelajari Pengaruh Pengolahan Tanah dan Cara Pemberian Air Terhadap Pertumbuhan Tanaman Cabai. (Capsicum annum L.) (in bahasa). J. Embryo. 8 (2): 32-39

[5] Intara Yazid I., A Sapei, Erizal, E. N Sembiring and M. B Joefrie. 2011. Pengaruh Pemberian Bahan Organik pada Tanah Liat dan Lempung Terhadap Kemampuan Mengikat Air (in Indonesia). JIPI. 11 (2): 52-56

[6] Intara Yazid I., A Sapei, Erizal, E. N Sembiring and M. B Joefrie. 2013. Pergerakan Air Irigasi Bawah Permukaan pada Tanah Liat yang Diolah Secara Strip untuk Memenuhi Kebutuhan Air Tanaman (in Indonesia). J. Teknotan. 8 (1): 21-27.

[7] Janovicek K J, Deen W, and Vyn T J. 2006. Soybean Response to Zone Tillage, Twin-Row Planting, and Row Spacing. American Society of Agronomy. Agron. J. (98);800-807.

[8] Jansen M E. 1983. Design and Operation of Farm Irrigation Sistem. AS,Michigan.

[9] Kelly T C, Lu Y and Teasdale J. 1996. Economic-Enviromental Tradeoffs Among Alternative Crop Rotation. J. Agric. Ecosyst. Envuron. (60); 17-28

[10] Miyazaki T, Hasegawa S, and Kasubuchi T. 1993. Water Flow in Soils. Marcel Dekker.

[11] Morrison J J Jr. 2002. Strip Tillage For "No-Till" Row Crop Production. Applied Engineering in Agriculture. J. American Society of Agricultural Engineers. (18); 277-284

[12] Mostaghimi S and Mcmahon P C. 1989. Surface and Subsurface Drainage Simulations for A Claypan Soil. J. Agricultural Water Management, (15); 211-222.

[13] Mukhtar S, Baker J L, Horton R and Erbach D C. 1985. Soil Water Infiltration as Affected by The Use of The Paraplow. Trans. ASAE, (28); 1811-1816.

[14] Strelkoff T S, Clemmens A J and Bautista E. 2004. Field-Parameter Estimation For Surface Irrigation Management and Design. J. Irrig. Drain. Eng., ASCE.

[15] Trouse A C Jr. 1983. Observations on Under-The-Row Subsoiling After Conventional Tillage. J. Soil Tillage Res., (3);67-81.

[16] Van Genuchten M. Th. 1980. A Close From Equation for Predicting The Hydraulic Conductivity of Unsaturated Soils. Soil Sci. Soc. An. J. (44); 892-898

[17] Yong R N and Warkentin B P. 1966. Introduction to Soil Behavior. The Macmillian Co. New York 